\title{
Cultura da mídia no livro didático de inglês: construindo letramentos críticos com professores em formação
}

\author{
Maria Gabriella Mayworm de Castro \\ Universidade Federal Fluminense \\ Ricardo Luiz Teixeira de Almeida \\ Universidade Federal Fluminense
}

\begin{abstract}
Resumo
Este estudo tem por objetivo fazer uma análise do papel da cultura midiática em um dos livros didáticos de inglês aprovados pelo PNLD 2014, por meio de discussões com professores em formação, em uma Universidade Federal. A investigação está fundamentada, teórica e metodologicamente, em pressupostos e princípios da Análise Crítica do Discurso, e busca contribuir de forma propositiva para o desenvolvimento de letramentos críticos no ensino de língua inglesa no contexto das escolas publicas brasileiras.
\end{abstract}

Palavras-chave: letramentos críticos, mídia, livro didáticos

\begin{abstract}
This paper aims at analyzing the role of media culture in one of the textbooks approved by the National Program of Textbooks (Programa Nacional do Livro Didatico - PNLD) in 2014, through discussions with future teachers taking their preservice education at a Federal University. The investigation is supported, both theoretically and methodologically, by assumptions and principles of Critical Discourse Analysis, and it is meant to contribute to the development of critical literacies in English classes in the context of Brazilian public schools.
\end{abstract}

Keywords: critical literacy, media, textbooks

\section{INTRODUÇÃO}

Este artigo tem como objetivo analisar o papel das culturas midiáticas em um dos livros didáticos de inglês do $9^{\circ}$ ano aprovados pelo PNLD 2014. Utilizaremos o aporte teóricometodológico da Análise Crítica do Discurso (FAIRCLOUGH, 1989, 1995, 2006), da Linguística Sistêmico-Funcional (HALLIDAY, 1985) e da Análise Multimodal do Discurso (KRESS e VAN LEEUWEN, 1996). Esta pesquisa tem uma perspectiva póscolonialista (MOITA LOPES, 2013) e se coloca no sentido de investigar e contribuir para a construção de letramentos críticos (CERVETTI, PARDALES e DAMICO, 2001) e multiletramentos (COPE e KALANTZIS, 2000) na aula de língua estrangeira. 
Esta pesquisa se situa no contexto da modernidade líquida (BAUMAN, 2000), na qual as identidades são múltiplas e fragmentadas, e nossa reflexividade é cada vez mais permeada por discursos midiáticos. Ou seja, nossa compreensão do mundo é em grande medida construída pela influência das mídias. Diante disso, e considerando a marcante presença das culturas midiáticas em livros didáticos, procuramos investigar como os discursos midiáticos aparecem no livro didático e como são problematizados pelo material e por professores em formação.

Esta pesquisa foi elaborada a partir de diálogos com professores em formação do curso de Letras Português-Inglês, em uma Universidade Federal, no último ano de sua licenciatura. Faremos neste artigo uma leitura do papel dos discursos midiáticos em algumas atividades de leitura do livro didático na interseção com as percepções e observações dos licenciandos. Duas atividades do LD foram analisadas pela turma de licenciandos.

Buscamos construir um estudo propositivo que possa servir para professores e pesquisadores a fim de contribuir para a construção de letramentos críticos e multiletramentos na aula de língua inglesa.

Com o advento e o desenvolvimento da rede mundial de computadores e suas tecnologias, as mídias contemporâneas deixaram de ser exclusivamente unidirecionais, como na era dos meios de comunicação de massas, e passaram a se caracterizar também e principalmente pela interatividade. Tais mudanças nas mídias de comunicação trazem também mudanças nas maneiras de construir sentidos e novas formas de ação social, como as que ocorrem por meio de novos gêneros discursivos digitais, tais como "comentários", "fóruns de discussão", a chamada "fan fiction", etc., gêneros que têm em comum a tomada da palavra por aqueles que, na era da comunicação de massa, ocupavam exclusivamente o lugar de espectadores. Sendo assim, os letramentos escolares devem buscar inserir o aluno em um mundo globalizado, tecnologizado e hipersemiotizado, para que ele seja capaz de ler criticamente os diversos discursos que circulam socialmente e perceber as implicações desses discursos na construção de futuros sociais (COPE e KALANTZIS, 2000).

\section{FUNDAMENTAÇÃO TEÓRICA}

Compreendemos letramentos, ou seja, as práticas sociais envolvendo línguas escritas e outros sistemas semióticos, com base no conceito de Multiletramentos, conforme Cope e 
Kalantzis (2000). Estes enfatizam a crescente diversidade linguística e cultural das comunidades afetadas pelo processo socioeconômico conhecido como globalização, além da multiplicidade de canais e meios de comunicação resultante das novas tecnologias. Complementamos o enquadre estabelecido pelas noções de letramentos e multiletramentos mencionadas acima com o conceito de letramentos críticos (CERVETTI, PARDALES e DAMICO, 2001). Fundamentado na crítica social, nos estudos de Paulo Freire e no pós-estruturalismo, este conceito se caracteriza pelo foco no empoderamento dos sujeitos sociais, a fim de que possam agir na sociedade por meio da linguagem, de forma a se posicionar criticamente e contribuir para as mudanças que considerarem desejáveis. São esses, portanto, os conceitos que utilizaremos para refletir sobre as propostas de letramento nos livros didáticos, tendo como foco a relação entre o ensino de língua inglesa e as culturas midiáticas.

Neste estudo entendemos como cultura midiática a cultura hegemônica, predominante nas mídias de massa, como a televisão (especialmente a TV aberta), o rádio, os jornais e revistas impressos, etc. Argumentamos que a presença de textos das novas mídias, como as redes sociais digitais (twitter e facebook, por exemplo), blogs, etc., que fazem parte de maneira contundente do cotidiano de muitas pessoas, é importante para o desenvolvimento dos letramentos dos alunos nas escolas públicas brasileiras. Sabendo disso, julgamos importante que os alunos sejam encorajados a perceber as fontes, as representações de mundo nos textos e os interesses aos quais essas representações podem atender.

Consideramos que as mídias constituem um grande campo de conflitos ideológicos, intertextualidades e novas formas de leitura que devem ser exploradas na escola. Avaliar a confiabilidade de uma fonte, perceber no hibridismo dos gêneros textuais os propósitos e estratégias dos autores, os discursos que constroem os textos e inclusive os discursos incoerentes, excludentes e problemáticos, são novos desafios para o leitor e precisam fazer parte das discussões de sala de aula para que, como usuários das novas mídias, os alunos sejam capazes de fazer leituras mais eficientes. Para isso julgamos que a presença de textos e discursos que circulam na grande mídia é um elemento que deve constituir a formação do aluno.

Com a retirada do texto de seu contexto de uso e sua transposição para o livro didático, é fácil que o aluno, e também o professor, percam de vista as relações existentes entre os textos dados e outros textos em seu contexto de uso "original". Os possíveis propósitos do texto e as representações de mundo nele construídas são elementos sócio-historicamente construídos e a 
percepção dessas construções históricas e sociais é indispensável para a formação de leitores. Sendo assim, compreender as mídias, culturas e os discursos a partir dos quais estamos produzindo leituras na sala de aula é o interesse principal desta investigação.

Entendemos que a cultura midiática hegemônica está intrinsecamente ligada ao mercado e ao consumo. O capitalismo tardio faz um grande investimento nas subjetividades (PELBART, 2000 apud ROCHA e CASTRO, 2009) como meios para se intensificar o consumo. Conforme Baudrillard (1997), o consumo é uma conduta ativa e coletiva, uma moral, uma instituição, é um sistema de valores cuja expressão implica a função de integração do grupo e também de controle social.

Fazer parte de um mercado consumidor significa fazer parte de determinados grupos sociais, o que pode influenciar o indivíduo a desejar e adotar determinadas identidades sociais e rejeitar outras. Suas crenças e valores passam a ser orientados por interesses mercadológicos, que podem até mesmo ir contra seus próprios interesses pessoais.

As formas de comunicação e os produtos midiáticos têm grande influência na formação das identidades, das relações, e das compreensões de mundo na sociedade tecnologizada. Por um lado, o sujeito contemporâneo tem acesso a diversas fontes e discursos, a recursos semióticos que podem compor suas identidades (BLOMMAERT, 2005) não mais localmente restritas. Por outro, torna-se fundamental enfrentar os processos de assujeitamento, percebendo e problematizando as construções sócio-históricas dos discursos e tornando visíveis formas contra-hegemônicas de subjetividade. Essa necessidade se intensifica à medida que se intensificam as estratégias propagandísticas, que muitas vezes se interconectam de forma quase indissociável a outros gêneros e passam a ser naturalizadas no cotidiano.

Conforme argumenta Rojo (2009), a globalização cultural já foi criticada por estudos sobre a indústria cultural e a comunicação de massas e, embora exista uma globalização das diversidades e da pluralidade cultural, predomina a globalização hegemônica, do apagamento das identidades locais, da "mcdonaldização" da cultura, tendo "como centro irradiador e dominante o ocidente, branco, masculino, heterossexual, norte-americano...". Ela é "padronizada, monofônica, homogênea e pasteurizada" (ROJO, 2009, p. 112). A indústria cultural midiática, como consequência de uma sociedade industrial neoliberal, busca, com seus produtos, "o reforço das normas sociais, repetidas até a exaustão, sem discussão.” (ROJO, 2009, p. 112), promovendo o conformismo e a alienação. 
Diante deste quadro, é preciso que os letramentos escolares dêem conta das diversas formas de expressão e construção de sentidos e dos diversos sistemas semióticos envolvidos nesse processo. Por isso, consideramos os multiletramentos e letramentos críticos como propostas pedagógicas que buscam dar conta das necessidades contemporâneas.

De acordo com Cope e Kalantzis (2000), é preciso pensar novas práticas de letramento considerando as diversas culturas que se expressam na língua inglesa e as rápidas mudanças nas formas de comunicação e conectividade. Sendo assim, os multiletramentos pretendem suplementar "formas tradicionais" ${ }^{1}$ de letramento no sentido de dar conta, principalmente, de dois aspectos da nova ordem social emergente: a multiplicidade das mídias que nos cercam e a diversidade cultural.

Na perspectiva dos multiletramentos (COPE e KALANTZIS, 2000), diante da globalização dos mercados e da interconectividade contemporânea, saber lidar com e construir sentidos a partir das diferenças linguísticas e culturais é crucial para a produtividade e a cidadania no mundo atual. Apesar de indicar também que o estudante se prepare para a inserção no mercado, que faz demandas por criatividade, diversidade, inovação etc, o projeto de multiletramentos, conforme Cope e Kalantzis (2005), se preocupa em não ser cooptado por discursos orientados pela marketização, e reforça o caráter crítico e emancipador que deve ter o ensino de línguas.

O conceito de letramento crítico aqui utilizado tem influência da teoria crítica social, principalmente no que se refere à busca por um mundo mais justo através da crítica e proposição de alternativas às desigualdades sociais (CERVETTI, PARDALES, DAMICO, 2001). Nesse sentido, o termo "crítico" refere-se à "problematização da opressão e da exploração, e à luta por uma sociedade melhor" (KELLNER, 1989, p. 46 apud CERVETTI, PARDALES, DAMICO, 2001). Segundo esses autores, as teorias críticas de letramento entendem que o sentido não é dado, único ou transparente, ele é construído no conflito entre diversas forças atuantes na sociedade e está ligado às lutas de poder. O sentido do texto é construído na leitura, está situado em contextos sócio-históricos e relações de poder, não está contido apenas nas intenções do autor.

\footnotetext{
${ }^{1}$ Ao usarem "formas tradicionais de letramento", os autores referem-se a práticas que levam em consideração apenas a forma escrita, e geralmente apenas uma variante linguística (a oficial e hegemônica).
} 
Dentro dessa perspectiva, a leitura é entendida como uma ação contextualizada sóciohistoricamente, na qual o leitor constrói sentidos e reflete sobre o texto levando em consideração as condições de produção, intencionalidades, ideologias e visões de mundo nele representadas (CERVETTI, PARDALES, DAMICO, 2001).

\section{METODOLOGIA}

Foram levados à aula da disciplina responsável pela organização, supervisão e reflexão teórico-prática sobre o estágio curricular obrigatório três textos retirados de um dos materiais didáticos aprovados pelo PNLD 2014, o livro Alive!, da editora SM-DIDÁTICOS (MENEZES, BRAGA, FRANCO, 2012). Cada grupo de alunos deveria escolher um dos textos oferecidos. O livro em questão foi selecionado por ter sido um dos mais escolhidos pelos professores de inglês em todo o Brasil, dentre as coleções aprovadas no PNLD 2014, tendo, assim, circulação nacional. Outro motivo por que selecionamos este livro é o fato de que ele traz diversos textos retirados de mídias sociais de grande circulação, o que consideramos importante para a inserção da escola no mundo globalizado e seu papel na reflexão sobre significados que circulam socialmente. O critério para a escolha dos textos, por sua vez, foi o seu potencial tanto para o ensino de cultura(s), quanto para a elaboração de atividades visando desenvolver letramentos críticos. Tendo cada grupo escolhido um texto, os alunos foram orientados a criar perguntas de compreensão sobre ele. Depois de discutir sobre o ensino de leitura, os objetivos do ensino de língua estrangeira na escola pública e os PCNs, os alunos se reuniram para elaborar as perguntas que seriam compartilhadas em um segundo encontro. $\mathrm{O}$ volume do livro utilizado foi o referente ao nono ano, ou seja, o volume destinado a alunos do último ano do ensino fundamental, estando direcionado, portanto, a alunos com mais condições de fazer leituras críticas, uma vez que já cursaram a maior parte do ensino fundamental.

Os três textos foram pré-selecionados para os licenciandos analisarem, utlizando como critério as possibilidades de problematização de identidades, papeis sociais e visões de mundo que percebemos nesses textos. São eles:

1) "Fallingwater" (história desta construção arquitetônica, página 110)

2) "Billy Elliot" (Sinopse do musical retirado do site Broadway.com, página 42)

3) “Being a Mommy and a Movie Star Is Hard” (Entrevista com Jennifer Lopez, página 69) 
Esses textos foram escolhidos por apresentarem diversas possibilidades de reflexão sobre diversidades culturais, de gêneros, classes sociais e discursos que poderiam se articular mais facilmente com as experiências dos alunos. Consideramos que o texto 3 (sobre Jennifer Lopez) poderia oferecer aos alunos a possibilidade de perceber e reelaborar conceitos de mulher, trabalho, maternidade, família, celebridades, música etc, e pensar sobre essas questões tendo em vista seu contexto social; já o texto 2 (sobre Billy Elliot) poderia levar à discussão sobre questões de gênero, estereótipos, escolha (ou não) de profissões, arte etc. Por fim, o texto 1 (sobre Fallingwater) poderia ser relacionado a questões de meio ambiente, arte, moradia, urbanização e natureza. Os alunos foram encorajados a criar propostas de intertextualidades e poderiam trazer outros textos para serem lidos junto com o texto dado. Observando a presença desses temas nos textos, verificaremos sob quais perspectivas eles são apresentados nos textos e nas perguntas de compreensão, e como são percebidos pelos alunos da graduação.

Apesar de serem dados 3 textos para 3 grupos, o mesmo texto poderia ser trabalhado por mais de um grupo, conforme desejassem. Dois grupos escolheram o texto sobre a obra Fallingwater e um escolheu o texto sobre Billy Elliot. Sendo assim, apenas duas atividades serão analisadas neste estudo. Uma das justificativas dos grupos para não terem escolhido o texto sobre Jennifer Lopez foi que consideraram que o tema era "um tanto alienado".

Em um segundo momento, cada grupo apresentou suas perguntas de compreensão sobre os textos do LD, justificando suas escolhas e refletindo sobre diversas possibilidades de leitura, e sobre a importância dos diversos tipos de atividades que poderiam ser propostas sobre o texto.

Em um terceiro momento, foram mostradas aos alunos as questões que o material didático apresentou como propostas de desenvolvimento da compreensão textual. Após analisarem essas questões, fizemos um grande debate compartilhando as reflexões feitas em cada grupo. Foram tomadas notas de campo sobre as falas dos licenciandos (ao todo 16 jovens adultos em fase de conclusão do curso de licenciatura) durante as discussões. Essas notas constituem, juntamente com o material escrito retirado do livro e aquele produzido pelos alunos, os dados desta análise.

\section{ANÁLISE}

O livro didático Alive!, do $9^{\circ}$ ano, tem como tema geral a "arte". Percebemos que este livro apresenta diversos textos da grande mídia e de mídias alternativas, o que é positivo para o 
desenvolvimento de multiletramentos e letramentos críticos. Contudo, é preciso chamar a atenção do aluno para os discursos e os propósitos desses textos, e é nesse sentido que desenvolvemos este estudo. Destacamos também que as mídias alternativas usadas como fonte, neste LD, são

principalmente corporativas, ou seja, promovem algum espetáculo (como no texto sobre "Billy Elliot"), celebridade (como Jennifer Lopez) ou cartão-postal (como é o caso de "Fallingwater") que tem reconhecimento e legitimação na indústria cultural. Não observamos a ocorrência de textos de mídias contra-hegemônicas, ou que promovessem produções culturais amadoras ou locais. A análise dos dados visa em primeiro lugar à descrição e interpretação da linguagem dos textos trabalhados, para em seguida explicar os efeitos de sentido quanto a identidades e visões de mundo veiculadas. Segue-se a esses procedimentos, a comparação entre as atividades propostas para os textos no material didático em questão e aquelas propostas pelos alunos, cujas vozes buscamos incorporar.

\section{Texto 1: Fallingwater}

O livro traz um texto do site oficial do cartão-postal. Podemos ver a imagem da construção "Fallingwater" e um pequeno texto sobre ela. Trata-se de uma construção luxuosa que chama a atenção pela arquitetura elaborada, integrada à natureza que a rodeia, e construída sobre um riacho. Junto ao texto há uma imagem da construção, na qual podemos ver sua sofisticação, a natureza que a rodeia e o riacho que a atravessa. Conforme o texto, uma das principais propostas dessa construção artística é chamar a atenção para a possibilidade de integração harmônica da construção urbana com a natureza, apesar de geralmente as construções civis depredarem a natureza.

Ela está localizada nos Estados Unidos e foi construída a pedido de Kaufmann que, para escapar das pressões da vida urbana, fez a solicitação ao arquiteto por uma moradia no lugar de sua antiga casa de campo.

Há diversas construções arquitetônicas em todo o mundo, feitas por diferentes pessoas, com diferentes materiais, usadas para diferentes propósitos, envolvendo práticas sociais e culturais particulares. A construção selecionada nesta seção de leitura está de acordo com o tema do livro didático "Arte", pois se refere a uma construção artística. Ainda assim, a escolha por essa construção indica a preferência por representar uma moradia famosa, cara e sofisticada, que hoje 
é um museu, no lugar de outras construções arquitetônicas mais populares. A representação de moradia, neste texto, é elitizada, pouco acessível e apresenta uma proposta de preservação ambiental e integração com a natureza quase impossível de ser praticada pelos alunos, que dificilmente se verão como atores sociais construtores da realidade social que veem representada nesse texto.

Há sete perguntas de compreensão textual propostas no livro para esse texto. A primeira pergunta se o aluno gostaria de morar em uma casa assim, e por quê. Avaliamos que este tipo de pergunta pode ser um ponto de partida para discussões sobre posicionamentos dos alunos, suas crenças e concepções de mundo. Entretanto, se não for discutida criticamente, acreditamos que esta pergunta pode ressaltar diferenças sociais de acesso a bens materiais, sem por em questão suas causas. As possibilidades de posicionamento dos alunos com relação ao texto são de admiração e aspiração a fazerem parte deste mundo social, ou de rejeição. Para a pergunta "Você gostaria de morar em um lugar assim?", as respostas ficam entre "Sim" e "Não". Mesmo a explicação da resposta requerida pelo "Por quê?" que se segue não nos parece suficiente para libertar o aluno dessa dicotomia, já que o enquadre da pergunta anterior é binário. Avaliamos que esta leitura é superficial e não contribui para letramentos críticos, mas para a valorização de culturas elitizadas.

Uma das perguntas que mais se aproximam de práticas de letramentos críticos indaga se o aluno concorda que os avanços tecnológicos quase sempre tem como consequência a depredação da natureza, e pede que sejam citados exemplos da região onde o aluno mora. Nessa questão, partindo de elementos do texto o aluno é provocado a pensar sobre seu contexto social, o que avaliamos como algo bastante positivo. Ainda assim, ele não é levado a examinar criticamente elementos do texto, como a pressuposição implícita, tanto nas imagens quanto nos elementos verbais, de que construções artísticas e em harmonia com a natureza são muito dispendiosas, o que as tornaria inacessíveis aos leitores, no caso, alunos brasileiros das classes populares.

Avaliamos que as três perguntas seguintes são voltadas para elementos específicos do texto, objetivos, do tipo “quem? onde? quando?" e sem maiores desenvolvimentos, não interferindo, portanto, nas (des)construções dos discursos presentes no texto ou nos posicionamentos dos alunos de forma significativa.

Por outro lado, há uma questão que mostra imagens de outras construções com vistas para belas paisagens. $\mathrm{O}$ aluno deve associar as imagens às suas respectivas descrições: $\mathrm{O}$ elevador 
Lacerda, o Museu de Arte Contemporânea (MAC), um hotel na Amazônia, uma casa em Swain's Lane, Londres, uma casa entre montanhas e um lago. Achamos positivo o uso de imagens nas atividades de compreensão textual. No entanto, a atividade é superficial e não propõe que o aluno perceba intertextualidades, pautadas pela relação entre arquitetura e conservação da natureza, com o texto principal da unidade. As imagens mostram construções turísticas brasileiras e estrangeiras. Nenhuma das imagens mostra construções populares com valor arquitetônico, ainda que seja possível encontrar exemplos dessas construções no Brasil mesmo, como é o caso da Casa de Pedra, na comunidade de Paraisópolis em São Paulo ${ }^{2}$. O conceito de Arte na arquitetura como criação da elite, produção oficialmente reconhecida, se expressa nas escolhas do livro didático nesta seção.

Por último, uma pergunta de compreensão textual indaga se o aluno conhece alguma construção que tenha uma vista da cidade. Esta pergunta aproxima o tema "paisagem" do contexto cultural do aluno, mas além de identificar construções que têm uma vista para a cidade, não se questionam a construção histórica e social da existência desses lugares ou as práticas sociais às quais servem, ou outras percepções do lugar como parte da vida social, de forma que a atividade de compreensão se mantém em uma análise superficial do texto. Por exemplo, as construções do livro e as citadas pelos alunos são turísticas? O que se faz nesses lugares atualmente? São museus, casas? Sempre serviram a esses propósitos? São moradias caras? São moradias acessíveis para todos? Como foi o processo de construção desses lugares? Quem tem acesso a eles e quem não tem? E por quê?

Os alunos da licenciatura consideraram que o texto trazia uma boa oportunidade para debater questões sobre moradia no Brasil e sugeriram intertextualidades com outros textos sobre moradias construídas com materiais alternativos e sustentáveis e também sobre moradias indígenas e em diversas partes do país, em áreas rurais e urbanas.

A partir das discussões, pudemos perceber a preocupação dos licenciandos em discutir temas socialmente relevantes e que levassem em consideração o contexto brasileiro em sua diversidade, tornando os alunos inclusive mais conscientes dessa diversidade e das diferentes condições de moradia em diferentes partes do país, e também aprofundar as discussões sobre sustentabilidade.

\footnotetext{
${ }^{2}$ A Casa de Pedra foi construída ao longo de mais de duas décadas por Estevão da Conceição, um brasileiro sem qualquer formação em Arquitetura. Sua semelhança com o estilo do arquiteto catalão Antonio Gaudi, contudo, tornou-a conhecida mundialmente.
} 
Uma das preocupações dos licenciandos se expressou na seguinte frase: "Importante é o aluno não pensar que aquilo é o ideal", referindo-se à construção Fallingwater. Esta fala de um dos graduandos refletiu sua preocupação para que os textos não fossem apresentados como se trouxessem modelos a serem desejados ou imitados, superiores a outros elementos locais, mas que as culturas dos alunos fossem valorizadas. Os licenciandos apontaram que Fallingwater representa um modelo de moradia acessível apenas a grupos economicamente privilegiados, e que a maioria dos alunos brasileiros de escolas públicas, de maneira geral, mora em construções muito mais simples. Tal diferença, dependendo de como o texto fosse abordado pelo professor e pelo LD, poderia representar para os alunos apenas um objeto de desejo de ascensão social e reforçar o distanciamento entre as classes que tem acesso a este tipo de moradia e as que não tem (no qual a maioria dos alunos brasileiros ficaria na situação desprivilegiada).

Os licenciandos apontaram para a falta de propósitos claros e socialmente relevantes para a leitura do texto. Algumas perguntas colocadas na discussão foram: Qual é a importância dos alunos lerem esse texto sobre "Fallingwater"? A partir dessa leitura, e das perguntas de compreensão escrita, quais compreensões o aluno pode construir que sejam relevantes no seu contexto social? Quais discussões ela pode provocar? Como ela pode contribuir para a formação dos alunos? A partir desses questionamentos, os licenciandos entenderam que o propósito desta seção de leitura parece ser a de ver uma construção luxuosa e sofisticada, e nada mais.

Percebemos que a presença deste texto no LD pode gerar discussões socialmente relevantes, mas elas precisam ser criadas pelo professor. Não encontramos nas perguntas de compreensão um direcionamento para o desenvolvimento de letramentos críticos.

O acesso às mídias de comunicação nos permite hoje ver diversas construções e formas de expressão em todo o mundo, e assim nos dá possibilidade de acesso a representações hegemônicas, canônicas, tradicionais e também a subculturas, visões locais, contra-hegemônicas etc. Esta atividade de compreensão escrita traz predominantemente representações canônicas de paisagens e construções turísticas. O tema central é um tipo de moradia praticamente inacessível ao aluno brasileiro, e representa uma arte também canônica, a ser admirada, e não construída pelos alunos. A forma de integração à natureza também é um requinte desta arte, não uma atitude alcançável para o aluno. Sendo assim, as possibilidades da globalização e do acesso às mídias são aproveitadas para trazer aos alunos representações de mundo mais elitizadas e tradicionais em vez de contextos culturais e sociais mais democráticos e participativos. 


\section{Texto 2: Billy Elliot}

O texto foi retirado da página do site da Broadway, e mostra a página da internet, com opções de navegação no site, uma imagem de Billy Elliot e o texto principal sobre o musical. Segundo o texto, o musical conta a história de um menino em uma pequena cidade de mineradores no norte da Inglaterra. A história se passa no contexto da greve histórica dos mineradores, e acompanha a vida de um menino em uma família de trabalhadores das minas, que vive a perda recente da mãe. O menino descobre um grande talento para a dança, e enquanto seu pai e seu irmão participam dos violentos piquetes e atividades de greve, Billy Elliot aprende balé secretamente com a ajuda de sua professora. Elliot evolui na dança, mas a situação da cidade onde vive vai ficando cada vez pior, e sua única chance parece ser a escola de balé, o Royal Ballet School, onde nenhum menino da classe trabalhadora jamais entrou. Além disso, o texto traz algumas impressões sobre a performance da peça.

O conhecido musical da Broadway é uma produção bastante divulgada pela grande mídia. Por um lado, esse texto reproduz discursos que já circulam repetidamente em meios de comunicação de massa, em vez de produções às quais os alunos dificilmente teriam acesso fora do espaço escolar. Por outro, o fato de tratar-se de uma obra de grade circulação social amplia as possibilidades de aproveitar o conhecimento prévio dos alunos sobre ela, e de conectar o conhecimento escolar aos discursos que circulam na indústria cultural, tendo em vista sua influência na construção de conhecimentos em vários grupos sociais. Além disso, o musical, assim como a resenha, trazem possibilidades de perceber e discutir a construção de identidades de gênero, as desigualdades, opressões e lutas sociais, e barreiras sociais de acesso ao conhecimento, à arte etc.

Há, junto ao texto verbal, uma imagem retirada do filme Billy Elliot, na qual o menino está em uma sala de balé, cercado de bailarinas. Na imagem, Elliot é o único menino. Percebemos nesta seção de leitura uma rica possibilidade de discutir construções de gêneros.

Destacamos, ainda, como já mencionamos, que se trata aqui de um texto retirado do site da Broadway, sobre o espetáculo que a companhia oferece. Sendo assim, a descrição do ato performático, que é muito positivo, pode estar ligado ao fato de que é interesse da companhia que as pessoas assistam à peça. Este dado é essencial para a compreensão do texto como prática 
discursiva, com propósitos específicos e relações intertextuais, mas não aparece nas perguntas de compreensão textual.

Ao se depararem com as propostas de leitura do material didático, os licenciandos perceberam que há muito mais questões objetivas (de retirar informações explícitas do texto) do que de reflexão e discussão. E comentaram: “As questões formais são importantes, mas não pode ter só isso", referindo-se ao grande número de questões sobre elementos linguísticos e de leitura superficial, e poucas sobre o os discursos veiculados no texto. De fato, à exceção das questões de pós-leitura, todas as questões de compreensão textual ou pedem elementos explícitos e objetivos, ou implicam que o aluno compreenda paráfrases. É o caso, por exemplo, da questão 2, letra a, que pede para completar a seguinte frase: "Billy Elliot is a young boy whose dream is to ___." O mesmo pode ser visto na questão 3, letra a, em que se pede para marcar como falsa ou verdadeira a seguinte frase: "The musical is based on a book." Os demais 5 itens dessa questão seguem a mesma linha.

O que percebemos na discussão em grupo foi que, de maneira geral, as perguntas são de busca de informações objetivas e voltadas para a forma. Aquelas nas quais o aluno deve contribuir mais com sua opinião pessoal, segundo os licenciandos, pouco ou nada tem a ver com o texto. Nas atividades sobre o texto de Billy Elliot, por exemplo, as perguntas trazidas pelo material didático nas quais os alunos são convidados a discutir, localizadas na pós-leitura, são:

1) Qual é o seu sonho?

2) Você acha que sofrerá preconceito para alcançar seu sonho?

3) Com que coisas as pessoas geralmente tem preconceito?

Essas perguntas são bastante subjetivas, e a resposta do aluno é pessoal, não precisando do texto para ser respondida. Marcuschi (2002), por exemplo, não considera que esse tipo de questão ajude na formação do leitor crítico, já que pode ser respondida sem que o aluno sequer tenha lido o texto. Sendo assim, as perguntas sobre o texto saltam de um nível muito superficial à extrapolação completa do texto, deixando de lado as questões em que o texto seria debatido, relacionado com outros textos e discutido com mais profundidade. É preciso reconhecer, contudo, que a questão 3, citada acima, ainda que possa ser respondida sem a leitura do texto, possui bom potencial para a reflexão sobre seu tema principal: o preconceito.

Para este texto, os licenciandos propuseram as seguintes perguntas:

1. O que dificultou a trajetória de Billy Elliot? 
2. Identifique e discuta estereótipos e homofobia no musical e na nossa sociedade.

3. Quais elementos influenciam as escolhas de nossas carreiras?

4. O pai resistiria da mesma maneira se ele quisesse ser boxeador, por exemplo? Por quê (não)?

Pelas perguntas propostas pelos licenciandos podemos perceber o quanto é difícil elaborar questões que visem o desenvolvimento da criticidade, sem perder de vista a materialidade do texto, já que várias delas poderiam sofrer críticas semelhantes às que aqui fizemos às propostas pelo livro didático. Por exemplo, a questão 3, a exemplo das questões de pós-leitura propostas pelo livro, não precisa do texto para ser respondida. Já a questão 4, à semelhança da pergunta "Você gostaria de morar em um lugar assim? Por quê?", proposta pelo livro para o texto "Fallingwater", limita as respostas ao binarismo de um "sim" ou "não". Contudo, acreditamos que os licenciandos apresentaram propostas mais próximas ao letramento crítico, ainda que algumas delas se assemelhem, para o bem e para o mal, com a questão 3 de pós-leitura do livro para o texto Billy Elliot, mencionada acima. Suas questões buscam abrir espaço para que os alunos exponham suas percepções sobre as representações das identidades de Billy e as relações entre o menino, sua família e a comunidade. As perguntas provocam a reflexão sobre as barreiras constituídas pela construção social da masculinidade, e pela pobreza, que são obstáculos para o desenvolvimento do dançarino. Além da influência da família e da comunidade na escolha das profissões, a restrição do acesso ao aprendizado de determinados ofícios e artes também é um fator determinante na definição das profissões dos indivíduos. E muitas vezes as opções de atuação profissional são bastante limitadas.

A pluralidade e a diversidade de ideias e representações sociais tornam-se elementos centrais na discussão com o grupo de licenciandos, no debate de estereótipos, preconceitos, profissões, classe social e identidades homoafetivas. Durante a discussão em grupo, foi colocada a importância de desconstruir estereótipos: o fato de Billy Elliot dançar balé não significa que ele seja homossexual. No entanto, aprofundando essa discussão, os alunos questionaram: "Mas se ele é homossexual e é efeminado, qual é o problema? O fato de ser homossexual e ter uma identidade efeminada, o torna menos respeitável? Por quê?"

Além de apresentarem as perguntas citadas acima, os alunos apresentaram uma matéria publicada na Folha de São Paulo intitulada "Mãe larga a vida na Bahia para ajudar filho a ser 
bailarino no Bolshoi”, que conta a história da família e as dificuldades enfrentadas para realizar o sonho do menino brasileiro.

As questões propostas pela turma demonstram seu interesse em relacionar os conteúdos do texto com questões locais, e que se aproximem do cotidiano dos alunos, dentro de uma perspectiva interlinguística e intercultural. Suas propostas buscam dar voz aos alunos para que exponham seus posicionamentos com relação às identidades, relações sociais e visões de mundo presentes no texto, refletindo sobre seu próprio contexto social e possivelmente reelaborando discursos cristalizados, percebendo exclusões e criando compreensões transformadoras e, assim, construindo futuros sociais mais inclusivos.

Há uma proposta de quebra do estereótipo de masculinidade que se destaca na imagem do filme, e a contextualização das condições sociais do dançarino. Dessa forma, o discurso midiático favorece a construção de discursos contra-hegemônicos e de diversidade de gênero, construções da masculinidade e feminilidade, classe social e acesso. Entretanto, a mediação da leitura pelos licenciandos aparece como elemento fundamental para a percepção das diversidades e dos sentidos que podem ser construídos no texto, pois as perguntas de compreensão textual não referem-se aos discursos de construção de identidades, gêneros, classes sociais, barreiras sociais etc.

\section{CONCLUSÃO}

Verificamos que os discursos corporativos da indústria cultural midiática, assim como representações de culturas elitizadas, podem ser discutidos criticamente e relacionados ao contexto social dos alunos. Entretanto, observamos poucas propostas de reflexão crítica explicitadas no livro do aluno. Elas surgiram, principalmente, dos professores em formação. Sem a figura do professor engajado na formação crítica, os textos aqui analisados poderiam reproduzir, em aula na escola pública, discursos alienadores e excludentes, uma vez que não enfatizam na análise textual o elemento histórico e social das construçõ es textuais e culturais. $\mathrm{O}$ predomínio de discursos da grande mídia e da elite estadunidense pode refletir um desequilíbrio na seleção de textos e culturas que devem compor a formação do aluno, a menos que esses textos sejam criticamente percebidos como construções culturais particulares, sócio-historicamente situadas. 
Apesar da potencialidade que alguns dos textos apresentam para a discussão de temas socialmente relevantes, em conformidade com as orientações das OCEM e dos PCN, o livro didático parece buscar isentar-se dos debates envolvendo conflitos e contradições sociais que constituem a pluralidade de ideias e discursos formadores da nossa sociedade. Sendo assim, esses materiais didáticos reproduziram, nos exemplos mostrados, discursos midiáticos e elitizados de maneira pouco crítica, refletindo nas perguntas de compreensão textual uma concepção de leitura como construção não dialógica e não questionadora.

Este estudo não teve o objetivo de fazer uma análise completa do livro didático em questão. Não temos uma visão geral das atividades de leitura do livro, embora acreditemos que estudos mais aprofundados seriam profíquos para o desenvolvimento de materiais mais conectados com o contexto social brasileiro e global. Não podemos dizer se os tipos de atividades aqui apontados são predominantes no LD ou não. Buscamos neste estudo mostrar apenas possibilidades de desenvolver letramentos críticos a partir do livro didático e mostrar pontos que precisam ser desenvolvidos para um ensino mais crítico de leitura em língua inglesa. Concluímos que o grupo de licenciandos em questão foi capaz de criar propostas dentro de uma pedagogia crítica, buscando principalmente conectar os conteúdos do livro ao conhecimento dos estudantes e da realidade brasileira. Por outro lado, alguns elementos de contextualização histórica e social dos textos dados no livro não foram percebidos. Ainda assim, os licenciandos puderam, a partir do material fornecido pelo LD, criar melhores atividades de leitura. Acreditamos, portanto, que o material didático é uma ferramenta importante a partir da qual professores e alunos desenvolverão conhecimentos. Sendo assim, quanto mais propostas de reflexão crítica o livro didático apresentar, mais o professor poderá aprofundar e desenvolver seus conteúdos. O diálogo com licenciandos contribuiu para percebermos o papel do professor como mediador e suas limitações, tendo em vista o tempo, o material disponível, as instituições de ensino etc.

Acreditamos que há outras habilidades a serem desenvolvidas no LD de língua estrangeira juntamente com a reflexão crítica. Ainda assim, ressaltamos que este estudo pretendeu investigar o desenvolvimento de letramentos críticos, tendo em vista o texto como elemento cultural e ideológico (BAKHTIN, 2002).

Por fim, esperamos que este estudo possa contribuir, principalmente para professores em formação inicial e continuada, com possibilidades de desenvolver letramentos críticos na aula de língua inglesa, apesar das limitações do LD, entre outras. Acreditamos ter contribuído também 
para mostrar pontos em que os livros didáticos voltados para o ensino de inglês como língua estrangeira em escolas públicas brasileiras podem ser desenvolvidos, e propostas de desenvolvimento que contribuam para uma formação mais crítica. Julgamos também que, no processo de formação de professores, é importante perceber os espaços de desvio nos quais o professor pode atuar apesar das restrições não só do material, mas das condições de trabalho como um todo.

\section{REFERÊNCIAS}

ALI, S. Critical Language Awareness in Pedagogic Context. In: English Language Teaching Vol. 4, No. 4; December 2011.

ALMEIDA, R. L. T. de. Entre o instrutor de línguas e o educador linguístico: perfis de licenciandos na formação inicial do professor de inglês. In: Ecos da Linguagem, p. 101-123, 2014.

BAKHTIN, M. Marxismo e filosofia da linguagem. São Paulo, SP: HICUTEC, 2002.

BAUDRILLARD, J. A arte da desaparição. Rio de Janeiro: Editora UFRJ, 1997.

BAUMAN, Z. Modernidade líquida. ZAHAR, 2000.

BLOMMAERT, J. Discourse: a critical introduction. Cambridge: Cambridge University Press, 2005.

BOURDIEU, P. A economia das trocas linguísticas: o que falar quer dizer. São Paulo: Editora da Universidade de São Paulo, 1996.

. O poder simbólico. DIFEL, 1989.

CERVETTI, G.; PARDALES, M. J.; DAMICO, J. S. A tale of differences: comparing the traditions, perspectives, and educational goals of critical reading and critical literacy. Reading Online, 4(9).

COPE, B.; KALANTZIS, M. Multitileracies: literacy learning and the design of social futures. Routledge, 2000. 
CORACINI, M. J. O processo de legitimação do livro didático na escola de ensino fundamental e médio: uma questão de ética. In: CORACINI, M. J. (org.). Interpretação, autoria e legitimação do livro didático. São Paulo: Pontes, 1999.

DAHER, D. C., FREITAS, L.M.A., SANT'ANNA, V.L.A. Breve trajetória do processo de avaliação do livro didático de língua estrangeira para a educação básica no âmbito do PNLD. Eutomia: Revista de Literatura e Linguística, Recife, 11 (1), p. 407-426, 2013.

DEBORD, G. A sociedade do espetáculo. Projeto periferia, 2003.

FAIRCLOUGH, N. Language and power. Longman, 1989.

. Critical discourse analysis: the critical study of language. New York: Longman, 1995

. Discourse and social change. Polity Press, 2006.

FREIRE, P. Educação como prática da liberdade. Rio de Janeiro: Paz e Terra, 1967 . Pedagogia do oprimido. Rio de Janeiro: Paz e Terra, 1968.

HALLIDAY, M.A.K. An introduction to functional grammar. London: British Library Cataloguing in Publication Data, 1985.

KLEIMAN, A. B. (Org.). Os significados do letramento. Campinas: Mercado de Letras, 1995.

KRESS, G. \& VAN LEEUWEN, T. Reading images: the grammar of visual design. London: Routledge, 1996.

MARCUSCHI, L. P. Compreensão de texto: algumas reflexões. In: DIONÍSIO, A. P.; BEZERRA, M. A. (orgs.). O livro didático de português: múltiplos olhares. Rio de Janeiro: Editora Lucerna, p.48-61, 2002.

MATTA, J. O. S. A cultura da mídia e celebridades (midiáticas) do contemporâneo: Madonna e Avril Lavigne. TecCom Studies. Estudios de tecnología y comunicación. Número 3 - Año 2, 2012.

MENEZES, V.; BRAGA, J.; FRANCO, C. Alive!: Inglês 9 ano. Editora UDP, 2012.

MOITA LOPES, L. P. A nova ordem mundial, os Parâmetros Curriculares Nacionais e o ensino de inglês no Brasil: a base intelectual para uma ação política. In: BARBARA, L.; RAMOS, R. Reflexões e Ações no Ensino-aprendizagem de Línguas. Homenagem a Antonieta Celani. Campinas: Mercado de Letras, 2003. 
. Oficina de Lingüística Aplicada. A natureza social e educacional dos processos de ensino/aprendizagem de línguas. Campinas: Mercado de Letras. 1996.

. Identidades fragmentadas: a construção discursive de raça, gênero e sexualidade na escola. Campinas: Mercado de Letras, 2002.

. Ideologia linguística: como construir discursivamente o português no século XXI. In: MOITA LOPES, L. P. (org.) O português no século XXI: cenário geopolítico e sociolinguístico. São Paulo: Parábola Editorial, p. 18-52, 2013.

OLIVEIRA, J. B. A.; GUIMARÃES, S. D. P.; BOMÉNY, H. M. B. A política do livro didático. São Paulo: Summus e Editora da Unicamp, 1984.

RESENDE, V. M., RAMALHO, V. Análise de discurso crítica. Editora Contexto, 2006.

ROCHA, R. de M.; CASTRO, G. G. S. Cultura da mídia, cultura do consumo: imagem e espetáculo no discurso pós-moderno. Logos, 30 (1), p. 48-99, 2009.

ROJO, R. H. R. (Org.) A prática de linguagem em sala de aula: praticando os PCNs. Campinas: Mercado de Letras/Educ, 2000. . Letramentos múltiplos, escolar e inclusão social. São Paulo: Parábola Editorial, 2009.

\section{OS AUTORES}

Maria Gabriella Mayworm de Castro é licenciada em Letras pela Universidade Federal Fluminense e aluna de mestrado do Programa de Pós-Graduação em Estudos de Linguagem da Universidade Federal Fluminense.

E-mail: mariagabriella@,id.uff.br

Ricardo Luiz Teixeira de Almeida é doutor em Letras pela Universidade Federal Fluminense e docente do Programa de Pós-Graduação em Estudos de Linguagem da Universidade Federal Fluminense.

E-mail: aricardo8@gmail.com 